\title{
Pápulas atróficas en pediatría
}

\section{Atrophic papules in pediatrics}

\section{María Florencia Martinez ${ }^{1}$, María Marta Buján ${ }^{2}$, María del Valle Centeno ${ }^{3}$ y Andrea Bettina Cervini ${ }^{4}$}

1 Jefa de Residentes, Servicio de Dermatología

${ }^{2}$ Médica de Planta, Servicio de Dermatología

${ }^{3}$ Médica de Planta, Servicio de Anatomía Patológica

4 Jefa del Servicio de Dermatología

Hospital Nacional de Pediatría, "Prof. Dr. Juan P. Garrahan",

Ciudad Autónoma de Buenos Aires, Argentina

\author{
Contacto del autor: María Florencia Martinez \\ E-mail: maildeflorencia@gmail.com \\ Fecha de trabajo recibido: $4 / 9 / 2020$ \\ Fecha de trabajo aceptado: 9/12/2020 \\ Conflicto de interés: las autoras declaran que no existe conflicto \\ de interés
}

Dermatol. Argent. 2020, 26 (4): 181-182

\section{CASO CLÍNICO}

Paciente de sexo femenino de 9 años que consultó por lesiones asintomáticas en el tronco, de dos meses de evolución y aparición espontánea sobre la piel sana. Estas lesiones eran pápulas redondeadas, bien delimitadas, de coloración blanquecina con ligero brillo (Foto 1). Algunas de ellas presentaban una escama fina en la superficie y en otras se observaba una discreta depresión de aspecto atrófico (Foto 2). Como antecedente, la paciente se encontraba en seguimiento por vitiligo en los párpados superiores de 2 años de evolución, en tratamiento con tacrolimus $0,03 \%$ en ungüento.

Se realizó una biopsia de piel de una de las lesiones atróficas, cuyo resultado histopatológico informó la presencia de un infiltrado linfocitario en banda perivascular y perianexial, homogeneización del colágeno de la dermis superficial, queratinocitos apoptóticos y degeneración vacuolar de la capa basal (Foto 3).

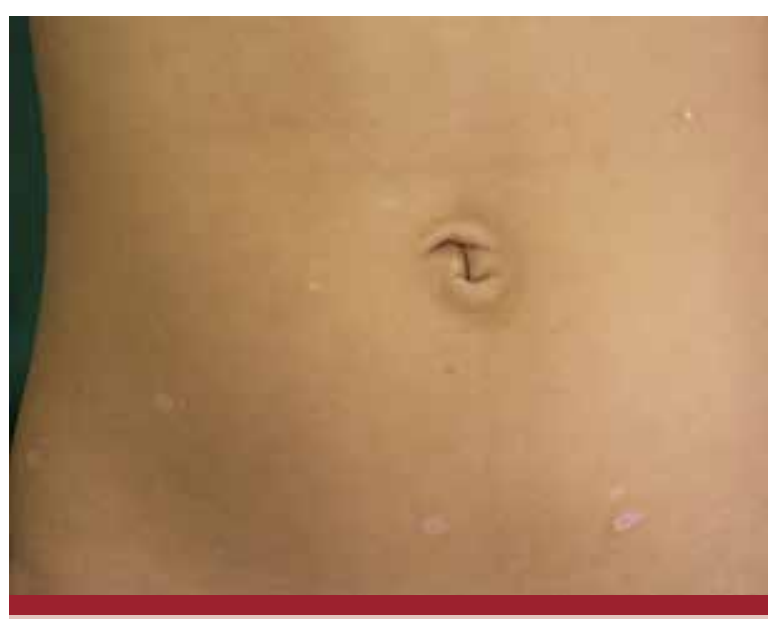

FОTO 1: Pápulas blanquecinas redondeadas, bien delimitadas, con ligero brillo, deprimidas y de aspecto atrófico de distinto tamaño en el abdomen.

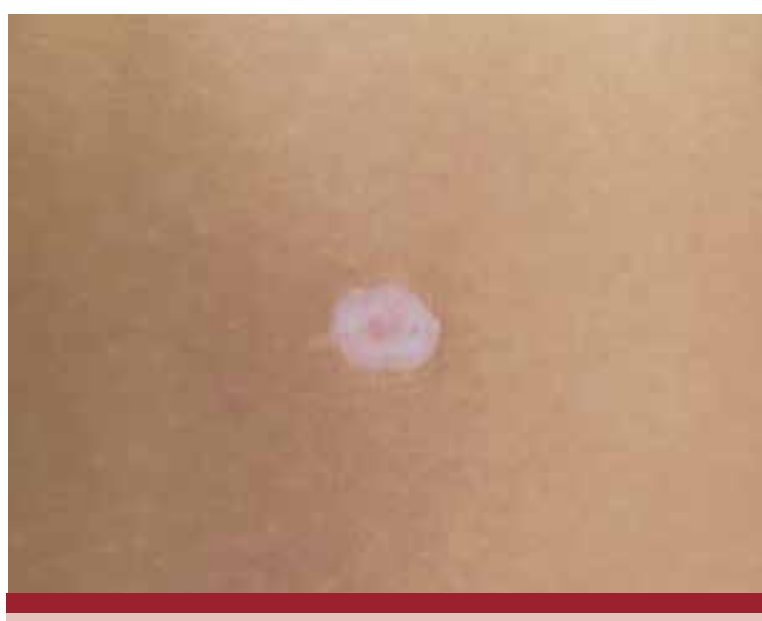

FOTO 2: Pápula blanquecina redondeada atrófica en el abdomen.

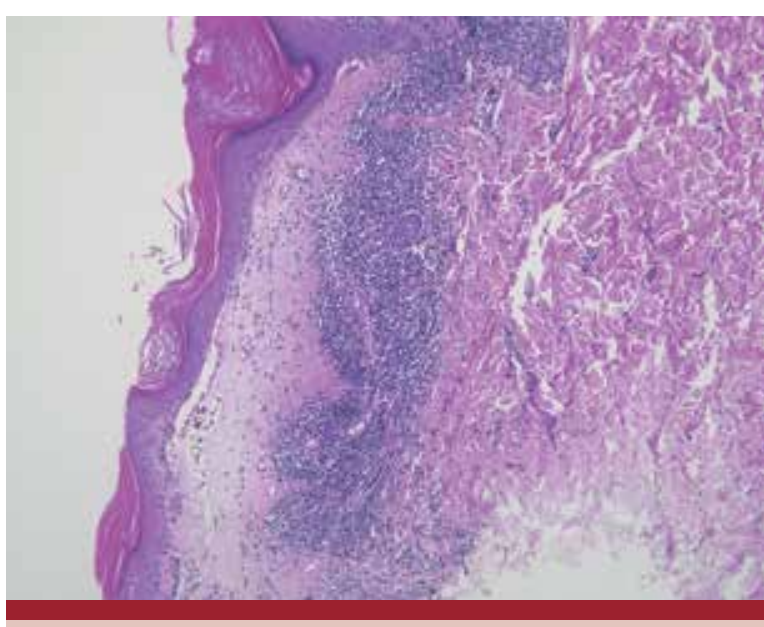

F0T0 3: Hiperqueratosis, atrofia epidérmica, homogeneización del colágeno, infiltrado inflamatorio de predominio mononuclear en la dermis superficial (HyE, 10X). 


\section{DIAGNÓSTICO}

Liquen escleroso extragenital.

\section{EVOLUCIÓN}

Como tratamiento del liquen escleroso extragenital y del vitiligo se indicó fototerapia (UVB de banda angosta), que cumplió de forma irregular. Luego de 3 meses desarrolló una lesión de liquen escleroso vulvo-anal por la cual inició, de forma simultánea a la fototerapia, tratamiento con clobetasol en crema. Lamentablemente no continuó con los controles y se perdió el seguimiento.

\section{COMENTARIOS}

El liquen escleroso (LE) es una enfermedad inflamatoria crónica, caracterizada por lesiones atróficas localizadas predominantemente en la región anogenital. También puede presentarse en sitios extragenitales (región cervical, porción superior del tronco, axilas y región periumbilical). Es más frecuente en el sexo femenino, en especial en la posmenopausia, y solo un 10 a $15 \%$ de los casos ocurren en la infancia ${ }^{1-4}$.

La etiología es desconocida. Se ha propuesto un origen multifactorial que incluye causas genéticas, autoinmunes, hormonales, infecciosas, traumáticas e irritantes crónicas ${ }^{1,2,4,5}$.

En la zona anogenital se presenta como una placa blanquecina brillante, indurada y de aspecto atrófico que adquiere una forma de 8 cuando afecta a la vulva y la región anal. Se puede asociar a prurito, dolor, disuria, erosiones y fisuras. Con el tiempo provoca graves secuelas estéticas y funcionales ${ }^{1,2}$.

La localización extragenital es más frecuente en adultos $(15-20 \%)$ que en niños $(10 \%)^{3}$. Puede estar asociada a lesiones anogenitales o no. Se manifiesta

\section{BIBLIOGRAFÍA}

1. Moreno M, Torrelo A, Mediero I, Zambrano A. Liquen escleroso y atrófico extragenital en niños. Actas Dermosifiliogr 2000;9:385-389.

2. Fich F, Giesen L, Navajas L, Mondaca L, et ál. Liquen escleroso y atrófico: revisión de una dermatosis con múltiples manifestaciones. Rev Chil Dermatol 2015;31:55-61.

3. Rodríguez-Acar $M$, Neri-Carmona $M$, Elizondo-Rodríguez $A$, Álvarez-Hernández MD, et ál. Liquen escleroso extragenital. Comunicación de un caso. Rev Cent Dermatol Pascua 2017;26:15-19.

4. CortésRos O,MatosFigueredoF,Gahona KrossT,Villacrés Medina L. Liquen escleroso atrófico genital y extragenital diseminado. como pápulas que pueden confluir y formar placas blanquecinas o eritematosas, con superficie atrófica ligeramente brillante y generalmente asintomáticas ${ }^{1-4,6}$. Las zonas afectadas con más frecuencia son el tronco superior, las axilas, la región cervical y la región abdominal, como se presenta en esta paciente ${ }^{2}$.

El diagnóstico del LE suele ser clínico cuando su presentación es típica. El estudio histopatológico es útil en caso de duda diagnóstica. Se observa atrofia epidérmica, degeneración vacuolar de la capa basal, infiltrado inflamatorio linfocitario en banda y homogeneización del colágeno en la dermis superficial ${ }^{2,7}$.

Los principales diagnósticos diferenciales son el liquen plano, la morfea y el vitiligo ${ }^{2,3}$.

El LE puede estar asociado a otras patologías, como tiroiditis, diabetes de tipo 1 , alopecia areata, anemia perniciosa y vitiligo, como es el caso de nuestra paciente ${ }^{1,6}$.

El tratamiento se basa en el uso de emolientes, corticosteroides tópicos de moderada o alta potencia, como propionato de clobetasol, e inhibidores de la calcineurina. La fototerapia con UVB-banda angosta o UVA-1 está indicada en áreas extragenitales cuando las lesiones son extensas ${ }^{3,7}$.

El LE tiene una evolución variable y puede remitir de manera espontánea o persistir con síntomas hasta la edad adulta. En los niños suele tener un mejor pronóstico que en los adultos, en dos tercios de las pacientes las lesiones se resuelven al llegar a la menarca ${ }^{1,3,7}$. El riesgo de desarrollo de carcinoma espinocelular en los niños es muy bajo, pero en los adultos es de hasta un $5 \%{ }^{1}$.

El diagnóstico y tratamiento temprano de esta patología podría prevenir las secuelas estéticas y funcionales, y reducir el riesgo de desarrollar un carcinoma espinocelular ${ }^{2}$.

Presentación de un caso. Medisur [en línea]. 2013; 11: 685689. Disponible en: http://scielo.sld.cu/scielo.php?script=sci_ arttext\&pid=S1727-897X2013000600010\&lng=es. [Consulta: agosto 2020].

5. Fistarol SK, Itin PH. Diagnosis and treatment of lichen sclerosus. Am J Clin Dermatol 2013;14:27-47.

6. Kirtschig G. Lichen sclerosus: presentation, diagnosis and management. Dtsch Arztebl Int 2016;113:337-343.

7. Lewis FM, Tatnall FM, Velangi SS, Bunker CB, et ál. British Association of Dermatologists guidelines for the management of lichen sclerosus. Br J Dermatol 2018;178:839-853. 